\title{
ON THE RELATIONSHIP OF SELF-SUFFICIENCY AND COMPETITIVENESS OF ECONOMY IN THE CONTEXT OF SOCIAL AND ECONOMIC DEVELOPMENT OF RUSSIA ${ }^{1}$
}

\author{
Aleksej M. Cikin \\ Financial University under the Government of the Russian Federation, Moscow, Russian Federation
}

\begin{abstract}
The aim of the article is to determine the concept of the socio-economic development of Russia on the basis of self-sufficiency and competitiveness, including resolving the antinomy of self-sufficiency and openness of the national economic system. As a methodological apparatus, the basic laws of dialectics are selected: the transition of quantitative changes to qualitative ones, the negation of negation, as well as the unity and struggle of opposites - in relation to Russian economy. As a result of the studies, it was found that the basis of the socioeconomic development of Russia in modern conditions is increasing the level of economic security, which can be defined as the sum of self-sufficiency and competitiveness of economy. The resolution of the antinomy of selfsufficiency and openness of the national economy in this case lies in the area of forming a strategy of controlled openness, which assumes the existence of the national economic system in the form of "soft autarky" based mainly on endogenous development factors, own resources and the domestic market. The fulfillment of these tasks is of particular importance in the context of modern geopolitical factors for the sectors of economy that are directly related to ensuring the country's defense capability and, in particular, the military-industrial complex. The results of the work can be used in the formation of state competitiveness management programs both at the federal level and in individual industries and regions.
\end{abstract}

Key words: self-sufficiency, competitiveness, national economy, socio-economic development, economic security.

Citation. Cikin A.M. On the Relationship of Self-Sufficiency and Competitiveness of Economy in the Context of Social and Economic Development of Russia. Journal of Volgograd State University. Economics, 2019, vol. 21, no. 4, pp. 36-43. (in Russian). DOI: https://doi.org/10.15688/ek.jvolsu.2019.4.4

\section{О СООТНОШЕНИИ САМОДОСТАТОЧНОСТИ И КОНКУРЕНТОСПОСОБНОСТИ ЭКОНОМИКИ В КОНТЕКСТЕ СОЦИАЛЬНО-ЭКОНОМИЧЕСКОГО РАЗВИТИЯ РОССИИ ${ }^{1}$}

\author{
Алексей Максимович Цикин \\ Финансовый университет при Правительстве Российской Федерации, г. Москва, Российская Федерация
}

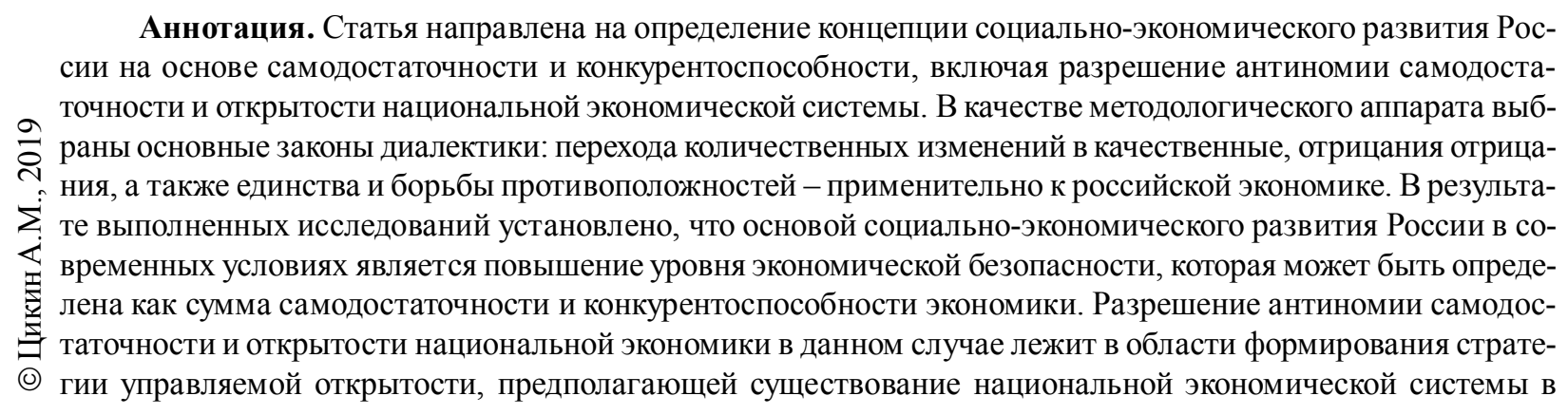


виде «мягкой автаркии», опирающейся преимущественно на эндогенные факторы развития, собственные ресурсы и внутренний рынок. Особое значение в контексте современных геополитических факторов выполнение данных задач имеет для секторов экономики, напрямую связанных с обеспечением обороноспособности страны и в частности оборонно-промышленного комплекса. Результаты работы могут быть использованы при формировании государственных программ управления конкурентоспособностью как на федеральном уровне, так и в отдельных отраслях промышленности и регионах.

Ключевые слова: самодостаточность, конкурентоспособность, национальная экономика, социальноэкономическое развитие, экономическая безопасность.

Цитирование. Цикин А. М. О соотношении самодостаточности и конкурентоспособности экономики в контексте социально-экономического развития России // Вестник Волгоградского государственного университета. Экономика. - 2019. - Т. 21, № 4. - С. 36-43. - DOI: https://doi.org/10.15688/ek.jvolsu.2019.4.4

\section{Введение}

Основополагающее значение при разработке концепции развития национальной экономики имеет трактовка самого понятия «национальная экономика». Парадигма эквивалентного обмена, являющегося базисом классической и неоклассической школы политической экономии, а также современного теоретического мейнстрима, не допускает саму постановку вопроса о самодостаточности и конкурентоспособности национальной экономики, что требует использования принципиально других подходов для разработки концепции развития российской экономики. Альтернативой мейнстримовой доктрине свободного рынка, эффективность на котором обеспечивается за счет абсолютных и сравнительных преимуществ, является неравновесная парадигма, которая представлена в трудах меркантилистов, представителей германской исторической школы и ограниченно - в кейнсианстве [Толкачев, 2008].

В развитие альтернативных подходов сегодня в трудах ведущих российских ученыхэкономистов предпринимаются попытки уйти от навязываемых извне идей неограниченно свободной торговли, использования сравнительных преимуществ, которые выражаются в специализации стран на «нужных» секторах экономики. Мировая практика показала, что при таком подходе основную выгоду от международных отношений получают страны с «лидирующими» экономиками, а периферия вынуждена сосредоточиться на производстве продукции (сырья и товаров низкого передела) с убывающей отдачей. Вследствие этого на рынках сбыта продукции периферии царит совершенная конкуренция, что приводит к падению реальных доходов и уровня жизни на- селения, а в конечном итоге и уровня развития национальной экономики.

Современные представления о развитии национальной экономики предполагают создание условий, при которых субъектам хозяйственной деятельности гарантируются фактически неограниченные экономические свободы, главной из которых является свобода от вмешательства государства в экономические процессы. На практике использование такого подхода часто приводит к тому, что мировая экономическая система характеризуется снижением уровня социальной ответственности, так как государства в современных международных отношениях стремятся к обогащению любой ценой, в том числе и за счет снижения качества жизни населения в странахконтрагентах. Однако именно социальная ответственность сегодня является неотъемлемым элементом развития национальной экономики. В свою очередь, повышение социальной ответственности многими учеными ставится в непосредственную взаимосвязь с развитием экономической безопасности.

Как отмечает М.И. Гельвановский, «на национальном уровне рыночные механизмы имеют определенные границы своего действия, обусловленные, прежде всего, необходимостью обеспечения национальной безопасности - фундамента социальной ответственности» [Гельвановский, 2017, с. 48]. Это обстоятельство подводит к тому, что обеспечение экономической безопасности страны является и одним из основных элементов конкурентоспособности национальной экономики. Развивая эти теоретические положения, М.И. Гельвановский трактует национальную конкурентоспособность как сумму эффективности и безопасности [Гельвановский, 2016, с. 18]: 


\section{ЭКОНОМИЧЕСКАЯ ТЕОРИЯ}

Конкурентоспособность $=$ $=$ Эффективность + Безопасность.

Тесную взаимосвязь понятий «конкурентоспособность национальной экономики» и «экономическая безопасность» анализирует в своей монографии А.А. Пороховский [Пороховский, 2002]. При этом в его работе конкурентоспособность национальной экономики наряду с социальной ответственностью определяет национальную экономическую безопасность. При этом автор отмечает, что именно поддержание экономической безопасности является ключевым элементом современной экономической политики США, Японии, новых индустриальных стран Юго-Восточной Азии, центральным вопросом развития которой (экономической безопасности. - А. Ц.) является формулирование и достижение национальных экономических интересов.

В контексте заявленной цели исследования понятия «экономическая безопасность» и «самодостаточность» (а также «конкурентоспособность») являются также непосредственно связанными. Наиболее релевантным определением экономической безопасности является «состояние национальной экономики, при котором обеспечивается гарантированная защита национальных интересов, устойчивое социально направленное развитие страны и достаточный оборонный потенциал даже при наиболее неблагоприятных условиях развития внутренних и внешних процессов» [Гельвановский, 2016, с. 16]. В работе под самодостаточностью национальной экономики понимается способность страны эффективно функционировать и решать социальные задачи при минимальной зависимости от иностранных контрагентов, в том числе при неблагоприятных внутренних и внешних факторах. Таким образом, национальная экономическая безопасность является суммой конкурентоспособности, характеризующей эффективность национальной экономической системы, и самодостаточности, способствующей устойчивости экономики:

Экономическая безопасность $=$
$=$ Конкурентоспособность + Самодостаточность.

В соответствии с предложенным подходом в современной России обеспечение эко- номической безопасности требует проведения полноценной деофшоризации, реализации стратегии управляемой открытости российской экономики и формирования программы поддержки отечественных производителей. В контексте темы исследования самодостаточность можно рассматривать как своеобразную «мягкую автаркию», которая, в отличие от классического определения [Большой энциклопедический словарь, 1993, с. 14], не предполагает минимизацию внешнего товарного оборота и взаимоотношений с другими странами. Вышеизложенные положения свидетельствуют о необходимости формирования стратегии развития российской экономики на основании диалектики самодостаточности и конкурентоспособности.

\section{Методика}

Многовековой опыт познания окружающей действительности свидетельствует о том, что основным методологическим аппаратом является диалектический (исторический) материализм [Ленин, 1973]. Соответствующие соображения в статье использованы для формирования концепции социально-экономического развития России в современных условиях. В контексте поставленной цели исследования в качестве основного методологического аппарата целесообразно использование основных диалектических законов: взаимного перехода количественных и качественных изменений, отрицания отрицания, а также единства и борьбы противоположностей [Суслов, 1983].

Переходы количественных изменений в качественные непосредственно характеризуют процесс развития мировой экономики. На определенном этапе совокупность накопленных количественных характеристик (например, концентрации капитала) приводит к формированию новой модели развития экономики (доиндустриальная $\rightarrow$ индустриальная $\rightarrow$ постиндустриальная $\rightarrow$ неоиндустриальная). В рамках новой модели, описываемой новым набором показателей и факторов развития, происходят количественные изменения уровня жизни населения, технологического уровня производств, человеческого потенциала и прочих параметров.

В соответствии с диалектическим законом отрицания отрицания развитие экономи- 
ческой системы идет от старого к новому, отрицающему черты прошлой модели. Такая логика позволяет увидеть историческую взаимосвязь экономических явлений и отношений, сформировать в рамках новых моделей положительные аспекты предыдущих подходов к обеспечению национального развития, гарантировать преемственность экономической политики государства. Закон отрицания отрицания наполняет смыслом и делает необходимым анализ закономерностей развития экономических отношений, выступающий основой формирования перспективных моделей национального развития.

Для анализа природы экономических явлений и отношений диалектический закон единства и борьбы противоположностей играет особую роль. В соответствии с ним любому социально-экономическому явлению присущи внутренние противоречия, являющиеся составными частями одного целого. Данные стороны находятся в непрерывной внутренней борьбе, которая выступает источником развития. В контексте развития национальной экономики в качестве таких противоречий целесообразно выделить самодостаточность и открытость социально-экономической системы, характеризующие принципиально разные подходы к развитию экономики.

\section{Результаты и обсуждение}

В соответствии с капиталистической моделью национальной экономики необходимой является безусловная открытость государственных границ для свободного перемещения капитала, товаров и людей. В то же время подобные подходы, распространяемые на все страны независимо от их уровня развития, на практике приводят к дальнейшему обогащению развитых стран и закреплению на периферии глобальной экономики государств, не достигших международной конкурентоспособности. В результате политики свободной торговли на мировом уровне большинство преимуществ получают страны, входящие в ядро капиталистической системы, в то время как уровень жизни в странах периферии неуклонно снижается. Альтернативным подходом является обеспечение самодостаточности национальной экономики, которая возможна и необходима в российских реалиях. Именно в диалектике самодостаточности и конкурентоспособности представляется развитие российской социально-экономической системы в целом.

Современная ситуация на мировых рынках показывает невозможность использования одинаковых методов управления национальным развитием для стран, находящихся в неравных исходных условиях. Одни и те же механизмы, применимые в развитых и развивающихся странах, приведут к кардинально противоположным результатам. В лидирующих мировых экономиках открытие границ и свободное движение товаров является необходимым условием роста национальной конкурентоспособности. За счет расширения рынков сбыта продукции национальные производители могут полноценно использовать эффекты масштаба, наращивая производственные мощности и увеличивая их загрузку. Кооперация с зарубежными партнерами позволяет получить сетевые и синергетические эффекты, связанные с передачей знаний и ресурсов по технологическим цепочкам [Audretsch et al., 2014].

Совершенно противоположный результат будет характерен для развивающихся стран, не достигших международной конкурентоспособности. Свободное обращение товаров в данном случае будет способствовать сворачиванию выпуска высокотехнологичных наукоемких товаров, для которых характерен положительный эффект масштаба, за счет невозможности противостоять в конкурентной борьбе крупным транснациональным корпорациям. В результате процессов деиндустриализации положение государства на периферии глобальной экономической системы будет закреплено, а конкурентоспособность снизится, в том числе и за счет ухудшения уровня жизни населения. Широкое использование математического аппарата для решения проблем экономического развития стран чревато тем, что исследователи будут двигаться по пути «наименьшего математического сопротивления», отбрасывая факты, которые не укладываются в продвигаемую теорию [Lawson, 2002].

На основе изложенных диалектических принципов актуальным является разрешение антиномии самодостаточности и открытости 
национальной экономики. Последняя характеристика является практически неотъемлемым свойством конкурентоспособности экономики в соответствии с представлениями зарубежных ученых. Первоначально в философии антиномия рассматривалась как противоречие, образуемое двумя суждениями, каждое из которых допускает одинаково убедительное логическое обоснование [Новейший философский словарь, 1998, с. 30]. Соответствующие противоречия характеризуют диалектический характер познания и в таком контексте анализ антиномии самодостаточности и открытости экономики ключ к пониманию процесса развития национальной экономики как проявления закона единства и борьбы противоположностей.

Сегодня становится очевидно, что антиномии характеризуют не только процесс диалектического познания, но и находят отражение в реальной жизни [Волков, 2008]. После распада СССР либертарианские идеи свободного рынка, провозглашаемого как всеобщее благо, на деле оказались воплощением экономических интересов узкой группы людей, при этом идеи и интересы другой, значительно большей части населения фактически не учитывались. Это обстоятельство привело к тому, что вопросы выбора генерального развития российской экономики сегодня остаются без ответа и предполагают использование различных, зачастую прямо противоречащих друг другу механизмов. Таким образом, Ж.Т. Тощенко определяет антиномичность как естественную характеристику кризисного развития общества, характерного для современной России [Тощенко, 2010].

В постсоветский период российская экономика столкнулась с практически неограниченно свободным глобальным рынком. При этом был выдвинут тезис о возможности авторегуляции конкурентоспособности российской экономики, что отвергало идею самодостаточности экономики. Однако исследования показывают, что современные процессы развития мировой экономики (в частности, глобализации) скорее повышают значимость факторов самодостаточности как национальной экономики, так и отдельных ее отраслей и предприятий [Bergman et al., 1999].

Диалектика российской конкурентоспособности и самодостаточности предполагает анализ исторического аспекта в процессе трансформации российских моделей развития национальной экономики. Невысокая конкурентоспособность и самодостаточность российской экономики в дореволюционный период стала одной из причин революции 1917 г. и потребовала от нового советского руководства ускоренного обеспечения национальной промышленности отечественными ресурсами. Благодаря выбранной политике наращивания самодостаточности экономики стало возможным в очень короткие сроки провести индустриализацию страны, ставшую одним из слагаемых в победе в Великой Отечественной войне. Продолжение этой политики в 1950-1960-х гг. предопределило восстановление российской экономики и выведение ее на ведущий мировой уровень с крайне высокими темпами экономического роста. Таким образом, для России исторически логичным является путь развития национальной экономики как автономной самодостаточной системы, предполагающей опору на эндогенные факторы конкурентоспособности, собственные ресурсы и внутренний рынок. В современных условиях самодостаточность экономики не предполагает изоляцию страны от глобального рынка, напротив, экспорт высокотехнологичной наукоемкой продукции должен быть максимально расширен, что позволит полнее использовать эффекты масштаба для повышения национальной конкурентоспособности. В таком контексте перспективы российской экономики целесообразно обозначить как «мягкую автаркию».

В то же время необходимо отметить, что современные геоэкономические и геополитические факторы (в частности, нестабильность внешней среды) обусловливают особую необходимость автаркии для ключевых секторов экономики, определяющих национальную безопасность, и в частности оборонно-промышленного комплекса. В постсоветский период именно оборонно-промышленный комплекс потерпел одни из наиболее существенных потерь в результате приватизации. Именно в нем наиболее ярко проявились негативные последствия разрыва хозяйственных связей, потери государственной собственности и утраты высококвалифицированных кадров, сопутствующие процессу распада СССР. Результатом современной государственной политики в от- 
ношении российской армии и обслуживающих производств стало значительное снижение обороноспособности страны, физический и моральный износ вооружения.

Для разработки стратегии обеспечения самодостаточности национального обороннопромышленного комплекса необходимо учесть негативные аспекты развития военно-промышленного комплекса СССР. В советский период военно-промышленный комплекс использовал ресурсы гражданского производства, фактически получая безвозвратные и беспроцентные кредиты [Лячин, 2011]. В данном случае peaлизовывался парадокс, когда наращивание затрат на национальную безопасность вызывает противоположный эффект, что в конечном итоге явилось одной из причин распада СССР с последующей деградацией некогда передового военно-промышленного комплекса.

Неповторение данной ситуации возможно при равном учете всех стадий процесса общественного воспроизводства при разработке стратегии национального развития. Стадия потребления играет в современном обществе важную роль, способствуя интенсификации воспроизводственного процесса и определяя конкурентоспособность как товаров, так и объектов более высокого уровня. В связи с этим побочной, но не менее важной функцией современного российского оборонно-промышленного комплекса является обеспечение технологического прогресса национальных производителей, ориентация на выпуск высокотехнологичной продукции, характеризующейся положительным эффектом масштаба.

В связи с изложенными причинами развитие и обеспечение самодостаточности оборонно-промышленного комплекса России очевидно. Связанные со снабжением армии промышленные предприятия представляют собой промышленный кластер, способный вызывать ускоренное развитие смежных отраслей народного хозяйства. Вовлечение в кластер предприятий оборонно-промышленного комплекса организаций других отраслей экономики приведет к ускоренному развитию конкурентоспособности страны на всех уровнях. Следует отметить, что оборонно-промышленный комплекс является одним из наиболее наукоемких сегментов экономики, требующих использования квалифицированных человечес- ких ресурсов. При этом наука в оборонной промышленности носит значительный прикладной характер, что обеспечивает повышение степени внедрения результатов НИОКР в практическую деятельность. Немаловажной особенностью предприятий оборонно-промышленного комплекса является то, что их развитие находится в русле выбранного вектора преодоления периферийного характера отечественной экономической системы, так как военная отрасль, как никакая другая, требует высокой степени локализации производств и самодостаточности экономической системы в целом.

Основным базисом развития обороннопромышленного комплекса является расширенное воспроизводство с акцентом на производство средств производства, что является безотлагательной задачей для российской экономики. Производство средств производства обеспечивает ориентацию деятельности национальной экономической системы не на финансовый, но на действительный результат. Следует отметить, что выбранный вектор приоритетного развития оборонно-промышленного комплекса, несомненно, требует соответствующего изменения поведения государства и частного бизнеса. Со стороны государства необходимо качественно изменить политику государственного регулирования экономики, сформировать четкую экономическую политику, повысить эффективность государственного контроля и надзора, особенно в финансовой сфере [Альпидовская и др., 2018].

\section{Выводы и рекомендации}

Таким образом, разрешение антиномии самодостаточности и открытости, а также их соотношение с конкурентоспособностью национальной экономики на основе основных диалектических законов представляется в виде формирования стратегии управляемой открытости российской экономики. Данная стратегия предполагает существование национальной экономической системы в виде «мягкой автаркии», опирающейся преимущественно на эндогенные факторы развития, собственные ресурсы и внутренний рынок. Основными направлениями повышения конкурентоспособности и самодостаточности россий- 
ской экономики при этом становятся поддержка опорных отраслей, повышение эффективности использования национальных ресурсов и содействие малому и среднему бизнесу как источнику инноваций в условиях цифровизации экономики. При этом не происходит изоляция страны, но трансформируется вектор экспортоориентации отечественной продукции с сырьевых товаров на продукцию высокого передела.

\section{ПРИМЕЧАНИЕ}

${ }^{1}$ Статья публикуется при поддержке гранта Российского фонда фундаментальных исследований (РФФИ) «Проблемы конфигурации глобальной экономики XXI века: идея социально-экономического прогресса и возможные интерпретации», № 18010-00877 A.

The article is funded by the grant of RFBR "Problems of the Configuration of the Global Economy of the $21^{\text {st }}$ Century: Idea of Socio-Economic Progress and Possible Interpretations", no. 18010-00877 A.

\section{СПИСОК ЛИТЕРАТУРЫ}

Альпидовская, М. Л. Конкурентоспособность национальной экономики: стратегии развития / М. Л. Альпидовская, А. М. Цикин. - Тверь : Твер. гос. ун-т, 2018. - 193 с.

Волков, А. И. Идеи правят миром / А. И. Волков // Экономика и общественная среда : Неосознанное взаимовлияние : научные записки и очерки. - М. : Ин-т экон. стратегий, 2008. - С. 27-67.

Гельвановский, М. И. Концепция макроконкурентоспособности как методологическая основа обеспечения экономической безопасности / М. И. Гельвановский // Экономическая безопасность России: проблемы и перспективы: материалы IV Междунар. науч.-практ. конф. - Н. Новгород : Нижегор. гос. тех. ун-т им. Р.Е. Алексеева, 2016. - С. 16-34.

Гельвановский, М. И. Методологические вопросы обеспечения финансово-экономической безопасности России / М. И. Гельвановский // Стратегические приоритеты. - 2017. - Т. 5, № 3. C. 44-53.

Ленин, В. И. Полное собрание сочинений / В. И. Ленин. - М. : Изд-вополит. лит., 1973.-- Т. 24. -567 с.

Лячин, В. И. Оборонная промышленность в структуре общественного воспроизводства / В. И. Лячин // Вестник Сибирского государственного аэрокосмического университета имени академика М. Ф. Решетнева. - 2011. - № 5 (38). С. 191-195.

Пороховский, А. А. Вектор экономического развития / А. А. Пороховский. - М. : ТЕИС, 2002.$304 \mathrm{c}$.

Суслов, И. П. Методология экономического исследования / И. П. Суслов. - М. : Экономика, 1983. $-215 \mathrm{c}$.

Толкачев, С. А. Глобализация и политическая экономия: в поисках новой конкурентной парадигмы / С. А. Толкачев // Капитал страны. Электрон. текстовые дан. - Режим доступа: http://kapital-rus.ru/articles/article/globalizaciya i_politicheskaya_ekonomiya_v_poiskah_ novoj_konkurentnoj_parad (дата обращения: 20.08.2019).

Тощенко, Ж. Т. Антиномия - новая характеристика общественного сознания в современной России / Ж. Т. Тощенко // Социологические исследования. - 2010. - № 12. - С. 3-17.

Audretsch, D. B. Technology transfer in a global economy / D. B. Audretsch, E. E. Lehmann, M. Wright // The Journal of Technology Transfer. - 2014. - Vol. 39, no. 3. - P. 301-312.

Bergman, E. M. Industrial and Regional Clusters: Concepts and Comparative Applications / E. M. Bergman, E. J. Feser // The Webbook of regional science. Morgantown : West Virginia University, 1999.

Lawson, T. Mathematical Formalism in Economics: what really is the problem? / T. Lawson // Methodology, Microeconomics and Keynes. L. : Routledge, 2002. - P. 73-83.

\section{ИСТОЧНИКИ И СЛОВАРИ}

Большой энциклопедический словарь / под ред. А. М. Прохорова. - М. : Сов. энцикл., 1993. $1628 \mathrm{c}$.

Новейший философский словарь / сост. А. А. Грицанов. - Минск : Издатель В.М. Скакун, 1998. $896 \mathrm{c.}$.

\section{REFERENCES}

Alpidovskaya M.L., Tsikin A.M. Konkurentosposobnost natsionalnoy ekonomiki: strategii razvitiya [Competitiveness of the National Economy: Development Strategies]. Tver, Tverskiy gosudarstvennyy universitet, 2018. 193 p.

Volkov A.I. Idei pravyat mirom [Ideas Rule the World]. Ekonomika $i$ obshchestvennaya sreda: Neosoznannoe vzaimovliyanie: nauchnye zapiski $i$ ocherki [Economy and Public 
Environment. Unconscious Mutual Influence. Scientific Notes and Essays]. Moscow, Institut ekonomicheskikh strategiy, 2008, pp. 27-67.

Gelvanovsky M.I. Kontseptsiya makrokonkurentosposobnosti kak metodologicheskaya osnova obespecheniya ekonomicheskoy bezopasnosti [The Concept of Macrocompetitiveness as a Methodological Basis for Ensuring Economic Security]. Ekonomicheskaya bezopasnost Rossii: problemy i perspektivy: materialy IV Mezhdunar. nauch.-prakt. konf. [Economic Security of Russia: Problems and Prospects. Proceedings of the $4^{\text {th }}$ International Scientific and Practical Conference]. Nizhny Novgorod, Nizhegorodskiy gosudarstvennyy tekhnicheskiy universitet im. R.E. Alekseeva, 2016, pp. 16-34.

Gelvanovsky M.I. Metodologicheskie voprosy obespecheniya finansovo-ekonomicheskoy bezopasnosti Rossii [Methodological Issues of Ensuring Financial and Economic Security of Russia]. Strategicheskie prioritety [Strategic Priorities], 2017, vol. 5, no. 3, pp. 44-53.

Lenin V.I. Polnoe sobranie sochineniy [Full Collection of Works]. Moscow, Izd-vo politicheskoy literatury, 1973, vol. 24. 567 p.

Lyachin V.I. Oboronnaya promyshlennost v strukture obshchestvennogo vosproizvodstva [The Defense Industry in the Structure of Social Reproduction]. Vestnik Sibirskogo gosudarstvennogo aerokosmicheskogo universiteta imeni akademika M. F. Reshetneva [Siberian Journal of Science and Technology], 2011, no. 5 (38), pp. 191-195.

Porokhovsky A.A. Vektor ekonomicheskogo razvitiya [Vector of Economic Development]. Moscow, TEIS Publ., 2002. 304 p.

Suslov I.P. Metodologiya ekonomicheskogo issledovaniya [Methodology of Economic
Research]. Moscow, Economika Publ., 1983. $215 \mathrm{p}$.

Tolkachev S.A. Globalizatsiya i politicheskaya ekonomiya: v poiskakh novoy konkurentnoy paradigmy [Globalization and Political Economy: In Search of a New Competitive Paradigm]. Kapital strany [Capital of the Country]. URL: http://kapital-rus.ru/articles/article/globalizaciya i politicheskaya ekonomiya v poiskah novoj konkurentnoj_parad/(accessed 20 August 2019).

Toshchenko Zh.T. Antinomiya - novaya kharakteristika obshchestvennogo soznaniya $\mathrm{V}$ sovremennoy Rossii [Antinomy - A New Characteristic of Social Consciousness in Modern Russia]. Sotsiologicheskie issledovaniya [Sociological Studies], 2010, no. 12 , pp. 3-17.

Audretsch D.B., Lehmann E.E., Wright M. Technology Transfer in a Global Economy. The Journal of Technology Transfer, 2014, vol. 39, no. 3, pp. 301-312.

Bergman E.M., Feser E.J. Industrial and Regional Clusters: Concepts and Comparative Applications. The Webbook of Regional Science. Morgantown, West Virginia University, 1999.

Lawson T. Mathematical Formalism in Economics: What Really Is the Problem? Methodology, Microeconomics and Keynes. London, Routledge, 2002, pp. 73-83.

\section{SOURCES AND DICTIONARIES}

Prokhorov A.M., ed. Bolshoy entsiklopedicheskiy slovar [Big Encyclopedic Dictionary]. Moscow, Sovetskaya Entsyklopedia, 1993. 1628 p.

Gritsanov A.A., ed. Noveyshiy filosofskiy slovar [The Latest Philosophical Dictionary]. Minsk, Izdatel V.M. Skakun, 1998. 896 p.

\section{Information About the Author}

Aleksej M. Cikin, Candidate of Sciences (Chemistry), Associate Professor, Doctoral Student, Department of Economic Theory, Financial University under the Government of the Russian Federation, Prosp. Leningradskiy, 49, 125993 Moscow, Russian Federation, tsikinalexey@mail.ru, https://orcid.org/0000-0003-4383-0373

\section{Информация об авторе}

Алексей Максимович Цикин, кандидат химических наук, доцент, докторант Департамента экономической теории, Финансовый университет при Правительстве Российской Федерации, Ленинградский просп., 49, 125993 г. Москва, Российская Федерация, tsikinalexey@mail.ru, https://orcid.org/0000-0003-4383-0373 